\title{
THE ACTIVITY OF DOSAGE INJECTION IN GENTAMICIN SULPHATE IN NACL AND DEXTROSE- NACL INFUSION AGAINSTBACILLUS SUBTILIS ATCC 6633 AND KLEBSIELLA PNEUMONIAE ATCC 2357
}

\author{
KURNIAWANSYAH I. S. , SULISTYANINGSIH, RAMADHANI N.
}

Faculty of Pharmacy, Universitas Padjadjaran, Sumedang, Indonesia

Email: insan.sunan.kurniawansyah@unpad.ac.id

Received: 11 Jul 2017, Revised and Accepted: 28 Nov 2017

\section{ABSTRACT}

Objective: The aim of the present study was to know the activity of injection preparation of gentamicin sulfate in varied intravenous fluids (NaCl and Dextrose- $\mathrm{NaCl}$ ) as well as variation of time of use against bacteria Bacillus subtilis and Klebsiella pneumoniae.

Methods: The research was a laboratory experiment with the following stages: 1.) mixing the sample performed in LAF, 2.) antibacterial activity test with time variation against Bacillus subtilis and Klebsiella pneumoniae bacteria, and 3.) analysis with ANOVA was needed to see if the infusion variation and time variation had a significant effect on gentamicin sulfate activity in killing Bacillus subtilis and Klebsiella pneumoniae bacteria.

Results: The mixing of gentamicin sulphate in both intravenous fluids for $2 \mathrm{~h}$ has a diameter of more than $20 \mathrm{~mm}$ inhibition. Gentamicin sulfate has decreased activity when mixed with intravenous fluids, both $\mathrm{NaCl} 0.9 \%$ and Dextrose $5 \%$ - $\mathrm{NaCl} 0.225 \%$. In both samples, there was a decrease in the inhibitory zone diameter of each mixing time increase. The first minute of mixing time gave the best effect, and the infusion variation had a significant effect only on gentamicin sulphate activity against Bacillus subtilis bacteria. Intravenous fluids Dextrose-NaCl gave a better effect than infusion of NaCl.

Conclusion: $\mathrm{NaCl}$ Infusion and Dextrose-NaCl had no effect on the activity of injection preparation of gentamicin sulfate against Klebsiella pneumoniae bacteria, but had an effect on Bacillus subtilis. The time of mixed use of gentamicin sulfate injection with NaCl and Dextrose-NaCl infusion fluid gave effect to its activity on Bacillus subtilis and Klebsiella pneumoniae bacterias, where the longer mixing time gentamicin sulphate activity decreased.

\section{Keywords: Antibacterial, Gentamicin sulphate, Dextrose-NaCl, Bacillus subtilis, Klebsiella pneumonia}

(c) 2018 The Authors. Published by Innovare Academic Sciences Pvt Ltd. This is an open access article under the CC BY license (http://creativecommons.org/licenses/by/4.0/) DOI: http://dx.doi.org/10.22159/ijap.2018v10i1.21256

\section{INTRODUCTION}

Respiratory infection is one of the most common diseases found in outpatients and inpatients throughout Indonesian hospitals. The most common bacteria causing respiratory infections are Bacillus subtilis for gram-positive and Klebsiella pneumoniae for gram-negative [1-3].

The use of antibiotics is still a major choice in the treatment of infectious diseases. In severe respiratory infections, patients are usually given antibiotic therapy gentamicin sulphate. Injection becomes the best choice for the administration of gentamicin sulfate because only less than $1 \%$ of the dose will be absorbed if administered orally and rectally and will penetrate very slowly if administered intradermally. In addition, gentamicin sulfate is formulated in the form of a dry injection dosage because it is unstable in the form of a solution $[4,5]$.

In hospitalized patients, gentamicin sulphate is administered intravenously and is usually combined with other intravenous preparations ( $\mathrm{NaCl}$, dextrose ringer, lactate ringer, etc.). This intravenous mixing should be done by a pharmacist at the Hospital Pharmacy Installation, but in fact, most are still implemented by other health workers with very limited means and knowledge. Preparation for this procedure has not been done with good aseptic techniques, whereas pharmaceutical work requires special techniques with sufficient knowledge such as sterility, physicochemical properties and drug stability, and also drug blindness and exposure to hazard risk. These techniques require specialized facilities and infrastructure that support the work to achieve sterility, stability, and drug confounding goals. Such a procedure aims to ensure the quality of drug preparation and sterility and the accuracy of dosage [6-8].

Some antibiotics are unstable in intravenous fluids and may reduce the activity of these antibiotics $[9,10]$. Based on a research that has been done by Saptarini, the type of infusion has a significant effect on decreased levels of gentamicin sulfate injection. Furthermore, a study by Pambudi showed that variations in intravenous fluids (ringer lactate and dextrose ringer) and time of dosage use have an effect on sterile injection dosage activity of gentamicin sulphate. According to Minister oh Health $(\mathrm{MOH})$ RI gentamicin sulfate is compatible (mixed) in $0.9 \% \mathrm{NaCl}$, 5\% Dextrose, Dextrose 10\%, Dextrose 5\%-NaCl 0.225\%, Ringer, and Ringer Lactate $[2,8,11]$.

Based on this background, research on the activity of injection preparation of gentamicin sulfate in varied intravenous fluids $(\mathrm{NaCl}$ and Dextrose- $\mathrm{NaCl}$ ) as well as variation of time of use against bacteria Bacillus subtilis and Klebsiella pneumoniae was conducted. The present study was expected to provide scientific information on the more appropriate types of intravenous fluids as solution to gentamicin sulfate injection preparations.

\section{MATERIALS AND METHODS}

\section{Tools}

The tools used in this research were Laminar Air Flow $\left(\right.$ Esco $^{\circledR}$ ), autoclave $\left(\mathrm{GEA}^{\circledR}\right.$ ), incubator (Memmert ${ }^{\circledR}$ ), oven (Memmert $854^{\circledR}$ ), microscope (Olympus ${ }^{\circledR}$ ), sterile petri dish (Pyrex) Sterile gauze, sterile gauze, sterile micropipette (Eppendorf ${ }^{\circledR}$ ), sterile reaction tube $\left(\right.$ Pyrex $\left.^{\circledR}\right)$, reaction tube rack, Erlenmeyer (Pyrex $\left.{ }^{\circledR}\right)$, perforator, sterile syringe (Terumo ${ }^{\circledR}$ Syringe), sterile ose, glass object.

\section{Materials}

The ingredients used in this study were injection of gentamicin sulphate (Sagestam ${ }^{\circledR}$ ), 0.9\% $\mathrm{NaCl}$ (Otsu-NS ${ }^{\circledR}$ ) and 5\%- $\mathrm{NaCl} 0.225 \%$ (Otsu-D5,1/4NS ${ }^{\circledR}$ ), Bacillus subtilis ATCC 6633 (Microbiology laboratory of Pharmacy Faculty of Universitas Padjadjaran) and Klebsiella pneumoniae ATCC 2357 (Microbiology laboratory of Pharmacy Faculty of Universitas Padjadjaran), sterile physiological NaCl (Otsu-NS ${ }^{\circledR}$ ), Nutrient Agar (NA) (Oxoid ${ }^{\circledR}$ ), Fluid Thioglycollate Medium (FTM) (Oxoid ${ }^{\circledR}$ ), and Tryptic Soya Broth (TSB) (Oxoid ${ }^{\circledR}$ ), Tryptic Soya Agar (TSA) (Oxoid ${ }^{\circledR}$ ). 


\section{Method}

The research was a laboratory experiment with the following stages:

\section{Laminar air flow sterility test}

The laminar air flow room was cleaned with $70 \%$ alcohol. Then UV and blower lights were turned on for $1 \mathrm{~h} .20 \mathrm{ml}$ of a sterile TSA medium was inserted into a sterile petri dish. After the media solidifies, the petri dish was opened and stored in the laminar air flow workspace for $15 \mathrm{~min}$. It was then subsequently incubated for $18-24 \mathrm{~h}$ at $37^{\circ} \mathrm{C}$ [7].

\section{Media fertility test}

Bacillus subtilis and Klebsiella pneumoniae were inoculated into 15 $\mathrm{ml}$ of FTM medium while Candida albicans was inoculated into $15 \mathrm{ml}$ TSB media. Further bacterial inoculation in FTM media was incubated for $7 \mathrm{~d}$ at $30-35{ }^{\circ} \mathrm{C}$ and inoculation of fungi on TSB medium was incubated for $7 \mathrm{~d}$ at $20-25{ }^{\circ} \mathrm{C}$ [12].

\section{Media effectiveness test}

Bacillus subtilis and Klebsiella pneumoniae were inoculated into 15 $\mathrm{ml}$ of FTM medium while Candida albicans was inoculated into $15 \mathrm{ml}$ TSB medium. $1 \mathrm{ml}$ test sample (gentamicin sulphate in $\mathrm{NaCl}$ and Dextrose- $\mathrm{NaCl}$ infusion liquids) was added to both media. Furthermore, bacterial inoculation in FTM media was incubated for $7 \mathrm{~d}$ at $30-35{ }^{\circ} \mathrm{C}$ and inoculation of fungi on TSB medium was incubated for $7 \mathrm{~d}$ at $20-25^{\circ} \mathrm{C}[12]$.

\section{Mixing sterile preparations}

$2 \mathrm{ml}$ injection solutions of gentamicin sulphate were dissolved in 100 $\mathrm{ml}$ of $0.9 \% \mathrm{NaCl}$ infusion and Dextrose $5 \%-\mathrm{NaCl} 0.225 \%$ in laminar air flow [7].

\section{Evaluation of gentamicin sulfate infusion dosage}

\section{Organoleptic}

Organoleptic observations were performed on the mixture of gentamicin sulfate injection with intravenous fluids, including form, clarity, odor, and color of preparations [12].

\section{Sterility test}

Samples were taken approximately $1 \mathrm{ml}$ and were then put into a test tube containing $15 \mathrm{ml}$ of FTM media and $15 \mathrm{ml}$ TSB media, respectively. Then the FTM medium was incubated at 30-35 ${ }^{\circ} \mathrm{C}$,whereas TSB medium was incubated at $20-25{ }^{\circ} \mathrm{C}$. Bacterial growth was observed in both media by looking at any turbidity for $14 \mathrm{~d}$ [12].

\section{Test for bacterial confirmation}

Biochemical tests conducted include carbohydrate fermentation test, proskauer voges test, methyl red test, and indole test performed by inserting 1 ose of bacteria into each medium. Motility tests were performed by inserting each 1 ose of bacteria. TSIA test, urease test, and citrate test were done by scraping bacteria on the media to tilt. Each test medium was incubated for $18-24 \mathrm{~h}$ at $37^{\circ} \mathrm{C}[13,14]$.

Gram staining was done by flooding the bacterial suspension with gentiant violet for $1 \mathrm{~min}$, rinsing it with distilled water, flooding it with lugol for $2 \mathrm{~min}$, and then rinsing it with distilled water. After that, the spread was rinsed again with $95 \%$ alcohol and distilled water. The streak was then flooded again with fuchsin water for $30 \mathrm{~s}$. The excess colour was removed and rinsed with distilled water. Then the glass object was drained and it spilled emersion oil. Then the glass object was observed under a microscope [15].

The activity of gentamicin sulfate injection in infusion preparations against Bacillus subtilis and Klebsiella pneumoniae

The method used was diffusion for perforation technique. $50 \mu \mathrm{l}$ of bacterial suspension (respectively Bacillus subtilis and Klebsiella pneumoniae) was mixed with $50 \mathrm{ml}$ sterile $\mathrm{NA}$ solution, then homogenized and allowed to solidify. Subsequently, holes were made on the agar medium by using a sterile perforator and in each hole was filled approximately $50 \mu \mathrm{l}$ injection of gentamicin sulfate mixed with $0.9 \%$ $\mathrm{NaCl}$ infusion and Dextrose 5\%- $\mathrm{NaCl}$ 0.225\% (respectively, with varying usage times for $0,30,60,90,120 \mathrm{~min}$ ) using a microphone. After that, it was incubated for $18-24 \mathrm{~h}$ at $37^{\circ} \mathrm{C}$. Furthermore, the inhibited zone formed was measured in diameter using a sliding term [16].

\section{Data analysis}

The data obtained (inhibitory diameter) was tested for normality and was analyzed using analysis of variance (ANOVA) with $\alpha$ of $5 \%$,and then proceed with the Tukey test [17].

\section{RESULTS AND DISCUSSION}

\section{Laminar air flow sterility testing}

There were 2 bacterial colonies on the sterility test results of laminar air flow space. According to Pharmacopeia Indonesia IV edition, this result met the requirements of laminar air flow as a class I or white area category, that was the number of microbes not more than 100 colonies [7].

\section{Media fertility test}

The media fertility test aimed to ensure that the FTM and TSB media used were capable of becoming the growth medium for microorganisms. The results of media fertility test can be seen in table 1 .

Table 1: Fertility test of FTM and TSB

\begin{tabular}{llll}
\hline Observation time (Day) & Media FTM & Media TSB (Candida albicans) \\
\cline { 2 - 3 } & Bacillus subtilis & Klebsiella pneumoniae & + \\
\hline 1 & + & + & + \\
2 & + & + & + \\
3 & + & + & + \\
7 & + & + & + \\
\hline
\end{tabular}

Notes: (+): there was growth of microorganisms, (-): no growth of microorganisms

Based on table 1, fertility test results indicated the presence of turbidity indicating the growth of microorganisms on the first day to the 7th $\mathrm{d}$ after incubation. Thus, it can be concluded that FTM and TSB media were fertile. It can be concluded that FTM and TSB media were fertile and met the requirements based on Pharmacopeia Indonesia IV edition, which can be used as media of microorganism growth if there is real growth in media within $7 \mathrm{~d}[12]$.

\section{Media effectiveness test}

Media effectiveness test was conducted to find out whether the media used were able to grow the microorganism after the addition of the test sample. Media effectiveness test results can be seen in table 2 and table 3 .

According to table 2 and table 3 , the results of media effectiveness test showed that bacterial growth on the 1 st $\mathrm{d}$ until the 7 th $\mathrm{d}$ after incubation occurred in FTM media, whereas fungal growth on the 5 th $d$ until the 7 th $d$ after incubation occurred in TSB media. This indicated that the FTM and TSB media were capable of growing microorganisms despite the addition of test samples. So when the sterility test in the sample mixing showed no indication of growth, it was not because the test sample contained antibiotics but because the sample mixing was sterile 
Table 2: Media effectiveness testing on gentamicin sulfate in $\mathrm{NaCl}$ infusion

\begin{tabular}{|c|c|c|c|}
\hline \multirow[t]{2}{*}{ Observation time (Day) } & \multicolumn{2}{|l|}{ Media FTM } & \multirow[t]{2}{*}{ Media TSB (Candida albicans) } \\
\hline & Bacillus subtilis & Klebsiella pneumoniae & \\
\hline 1 & + & + & - \\
\hline 2 & + & + & - \\
\hline 3 & + & + & - \\
\hline 5 & + & + & + \\
\hline 7 & + & + & + \\
\hline
\end{tabular}

Notes: (+): there was growth of microorganisms, (-): no growth of microorganisms

Table 3: Media effectiveness testing on gentamicin sulfate in Dextrose- $\mathrm{NaCl}$ infusion

\begin{tabular}{llll}
\hline Observation time (Day) & \multicolumn{2}{l}{ Media FTM } & Media TSB (Candida albicans) \\
\cline { 2 - 3 } & Bacillus subtilis & + & - \\
\hline 1 & + & + & - \\
3 & + & + & + \\
5 & + & + & + \\
7 & + & + & + \\
\hline
\end{tabular}

Notes: (+): there was growth of microorganisms, (-): no growth of microorganisms

Based on the result of fertility test and media effectiveness test, FTM and TSB can be used as media for sterility test because these media have fulfilled the requirement according to Pharmacopeia Indonesia IV edition, which was the media that were able to grow microorganism both for $7 \mathrm{~d}$ after incubation for fertility test and $7 \mathrm{~d}$ after incubation for effectiveness test $[7,12]$.

\section{Evaluation of gentamicin sulfate infusion dosage}

Sample mixing was done in the laminar air flow workspace to prevent contamination of microorganisms from the environment and air. The mixing results of gentamicin sulfate injection with intravenous fluids should be kept sterile because it will be used intravenously, directly on the blood vessels [7].

The mixing was done by introducing $2 \mathrm{ml}$ of $40 \mathrm{mg} / \mathrm{ml}$ gentamicin sulfate injection into each $100 \mathrm{ml}$ of $0.9 \% \mathrm{NaCl}$ infusion and Dextrose
$5 \%-\mathrm{NaCl} 0.225 \%$. The sample mixing results were then evaluated organoleptically for $2 \mathrm{~h}$ and tested for $14 \mathrm{~d}$ for sterility. This evaluation was performed to maintain the quality of the mixing of gentamicin sulfate in intravenous fluids.

The organoleptic dosage evaluation was performed for $2 \mathrm{~h}$ because gentamicin sulphate infusion was administered only briefly (intermittent infusion), which is less than $6 \mathrm{~h}$ per dose. According to USP, gentamicin sulfate was administered by infusion for $30 \mathrm{~min}$ to $2 \mathrm{~h}$ [11].

Table 4 and table 5 showed that the mixing results of gentamicin sulfate with each infusion fluid of $0.9 \% \mathrm{NaCl}$ and Dextrose $5 \%-\mathrm{NaCl}$ $0.225 \%$ for $2 \mathrm{~h}$ have fulfilled the requirements organoleptically as sterile injection preparations based on Pharmacopeia Indonesia IV edition, (i.e. stable in experiencing changes in dosage form), clear, odorless, and free of foreign particles [11].

Table 4: Testing of organoleptic gentamicin sulfate in $\mathrm{NaCl}$ infusion

\begin{tabular}{|c|c|c|c|c|}
\hline \multirow[t]{2}{*}{ Observation time (Min) } & \multicolumn{4}{|c|}{ Observational characteristics } \\
\hline & Form & Colour & Clarity & Smell \\
\hline 0 & Liquid & colorless & Clear & No smell \\
\hline 30 & Liquid & colorless & Clear & No smell \\
\hline 60 & Liquid & colorless & Clear & No smell \\
\hline 90 & Liquid & colorless & Clear & No smell \\
\hline 120 & Liquid & colorless & Clear & No smell \\
\hline
\end{tabular}

Table 5: Testing of organoleptic gentamicin sulfate in NaCl-drip-infusion

\begin{tabular}{|c|c|c|c|c|}
\hline \multirow[t]{2}{*}{ Observation time (Min) } & \multicolumn{4}{|c|}{ Observational characteristics } \\
\hline & Form & Colour & Clarity & Smell \\
\hline 0 & Liquid & colorless & Clear & No smell \\
\hline 30 & Liquid & colorless & Clear & No smell \\
\hline 60 & Liquid & colorless & Clear & No smell \\
\hline 90 & Liquid & colorless & Clear & No smell \\
\hline 120 & Liquid & colorless & Clear & No smell \\
\hline
\end{tabular}

Table 6: Sterility testing of samples

\begin{tabular}{llll}
\hline Observation time (d) & Sample 1 & \multicolumn{2}{c}{ Sample 2 } \\
\cline { 2 - 4 } & FTM & TSB & - \\
\hline 1 & - & - & - \\
2 & - & - & - \\
3 & - & - & - \\
5 & - & - & - \\
7 & - & - & - \\
10 & - & - & - \\
14 & - & - & - \\
\hline
\end{tabular}

Notes: (+): there was growth of microorganisms, (-): no growth of microorganisms, Sample 1: gentamicin sulphate in NaCl infusion 0.9\%, Sample 2: gentamicin sulphate in intravenous Dextrose $5 \%-\mathrm{NaCl} 0.225 \%$ 
Based on table 6 it could be seen that there was no growth of microorganisms in both samples (a mixture of gentamicin sulphate with $0.9 \% \mathrm{NaCl}$ infusion and a mixture of gentamicin sulphate with Dextrose $5 \%-\mathrm{NaCl} 0.225 \%$ infusion) in FTM and TSB media until day 14 after incubation. This indicated that the mixing results of gentamicin sulfate injection, with each of the two intravenous fluids, were sterile and it met the requirements in accordance with the provisions in Pharmacopoeia Indonesia IV edition which states that there was no growth of observed microorganisms on FTM and TSB media after incubation for not less than $14 \mathrm{~d}$ [11].
With the completion of organoleptic and sterility requirements, a mixture of gentamicin sulfate with each infusion of $0.9 \% \mathrm{NaCl}$ and Dextrose $5 \%-\mathrm{NaCl} 0.225 \%$ can be used by intravenous injection intravenously.

\section{Test for bacterial confirmation}

Metabolism or biochemical activity usually produces products that can be used for bacterial identification and characterization. The results of biochemical tests of Bacillus subtilis and Klebsiella pneumoniae bacteria can be seen in table 7 .

Table 7: Biochemical test of bacteria

\begin{tabular}{|c|c|c|c|c|}
\hline \multirow[t]{2}{*}{ Test } & \multicolumn{2}{|c|}{ Bacillus subtilis } & \multicolumn{2}{|c|}{ Klebsiella pneumoniae } \\
\hline & $*$ & Test & $* *$ & Test \\
\hline Saccharose & + & + & + & + \\
\hline Glucose & + & - & + & + \\
\hline Mannose & + & + & + & + \\
\hline Maltose & + & + & + & + \\
\hline Lactose & $+/-$ & - & + & + \\
\hline$V P$ & + & + & + & - \\
\hline$M R$ & - & - & - & - \\
\hline Indol & - & - & - & - \\
\hline Motility & - & - & - & - \\
\hline TSIA & - & - & + & + \\
\hline Urease & - & - & + & - \\
\hline Citric & + & + & + & + \\
\hline
\end{tabular}

Notes: *: Reference [18], **:Reference [19]

The results of biochemical tests in table 7 gave the appropriate results, the test bacteria were indeed bacteria Bacillus subtilis and Klebsiella pneumoniae. In addition, another test carried out in bacterial affirmation was Gram staining. Gram staining of Bacillus subtilis bacteria produced a purple color (in accordance with the primary dye) in the form of bacilli, meaning that the bacterium was a Gram-positive bacterium [18]. Gram staining of the bacteria Klebsiella pneumoniae produced a red color (corresponding to secondary color) in the form of short bacillus such as coccus [19]. This indicated that the bacteria were Gram-negative bacteria. Based on the results of biochemical tests and Gram staining, it can be confirmed that the bacteria used were true bacteria Bacillus subtilis and Klebsiella pneumoniae.

\begin{abstract}
The activity of gentamicin sulfate injection in infusion preparations against Bacillus subtilis and Klebsiella pneumoniae
\end{abstract}

Activity tests were performed to compare the antibacterial activity of gentamicin sulfate in an infusion of $0.9 \% \mathrm{NaCl}$ with intravenous fluids $5 \%-\mathrm{NaCl} 0.225 \%$ dyestuff so that the mixing of infusion fluid with gentamicin sulphate could be seen better. In addition, the optimum time of the use of the mixture can be seen with the sample activity test on the time variation. Results of gentamicin sulfate activity test in intravenous fluids can be seen in table 8 and table 9.

Table 8: Activity samples with variations of time to Bacillus subtilis

\begin{tabular}{|c|c|c|}
\hline \multirow[t]{2}{*}{ Sample } & \multicolumn{2}{|c|}{ Inhibition zone diameter of Gentamicin Sulfate in infusion } \\
\hline & $\mathrm{NaCl} \mathrm{0.9 \%}(\mathrm{mm})$ & Dextrose 5\%-NaCl 0.225\% (mm) \\
\hline Mixed minute 0 & $25.60+0.61$ & $26.94+0.14$ \\
\hline Mixed minute $30^{\text {th }}$ & $24.95+0.28$ & $25.57+0.12$ \\
\hline Mixed minute $60^{\text {th }}$ & $23.64+0.45$ & $24.76+0.15$ \\
\hline Mixed minute $90^{\text {th }}$ & $23.04+0.08$ & $23.46+0.17$ \\
\hline Mixed minute $120^{\text {th }}$ & $20.97+0.81$ & $22.24+0.57$ \\
\hline
\end{tabular}

Table 9: Activity samples with variations of time to Klebsiella pneumoniae

\begin{tabular}{lll}
\hline Sample & \multicolumn{2}{l}{ Inhibition zone diameter of Gentamicin Sulfate in infusion } \\
\cline { 2 - 3 } & $\mathbf{N a C l ~ 0 . 9 \% ( \mathbf { m m } )}$ & Dextrose 5\%-NaCl 0.225\% (mm) \\
\hline Mixed minute 0 & $25.24+0.71$ & $25.09+0.69$ \\
Mixed minute $30^{\text {th }}$ & $24.17+0.58$ & $24.17+0.54$ \\
Mixed minute $60^{\text {th }}$ & $23.14+0.71$ & $23.08+0.43$ \\
Mixed minute $90^{\text {th }}$ & $21.43+0.21$ & $21.83+0.63$ \\
Mixed minute $120^{\text {th }}$ & $20.43+0.29$ & $20.55+0.59$ \\
\hline
\end{tabular}

From table 8 and table 9 it can be seen that the mixing of gentamicin sulphate in both intravenous fluids for $2 \mathrm{~h}$ has a diameter of more than $20 \mathrm{~mm}$ inhibition. Based on the size of the inhibitory zone diameter, gentamicin sulphate in $0.1 \% \mathrm{NaCl}$ infusion fluid, as well as Dextrose $5 \%-0.225 \% \mathrm{NaCl}$, were categorized as having very strong activity, therefore it can still be used in medicine. This antibacterial power strength category was based on the classification of Davis and Stout. Antibacterial activity was said to be weak when the inhibitory zone diameter was $<5 \mathrm{~mm}$, mild when the inhibitory zone diameter was $5-10 \mathrm{~mm}$, strong when the inhibitory zone dimension was 10-20 
$\mathrm{mm}$, and very strong when the drag zoneis $20-30 \mathrm{~mm}$ [16]. In addition, gentamicin sulfate can be seen in both intravenous fluids, giving a larger inhibitory zone of Bacillus subtilis bacteria than Klebsiella pneumoniae. This indicated that gentamicin sulphate in
$\mathrm{NaCl}$ or Dextrose- $\mathrm{NaCl}$ infusion had better and more effective activity in Bacillus subtilis bacteria than Klebsiella pneumoniae. The graph of activity of gentamicin sulphate in $\mathrm{NaCl} 0.9 \%$ infusion fluid and Dextrose $5 \%-\mathrm{NaCl} 0.225 \%$ for $2 \mathrm{~h}$ can be seen below:

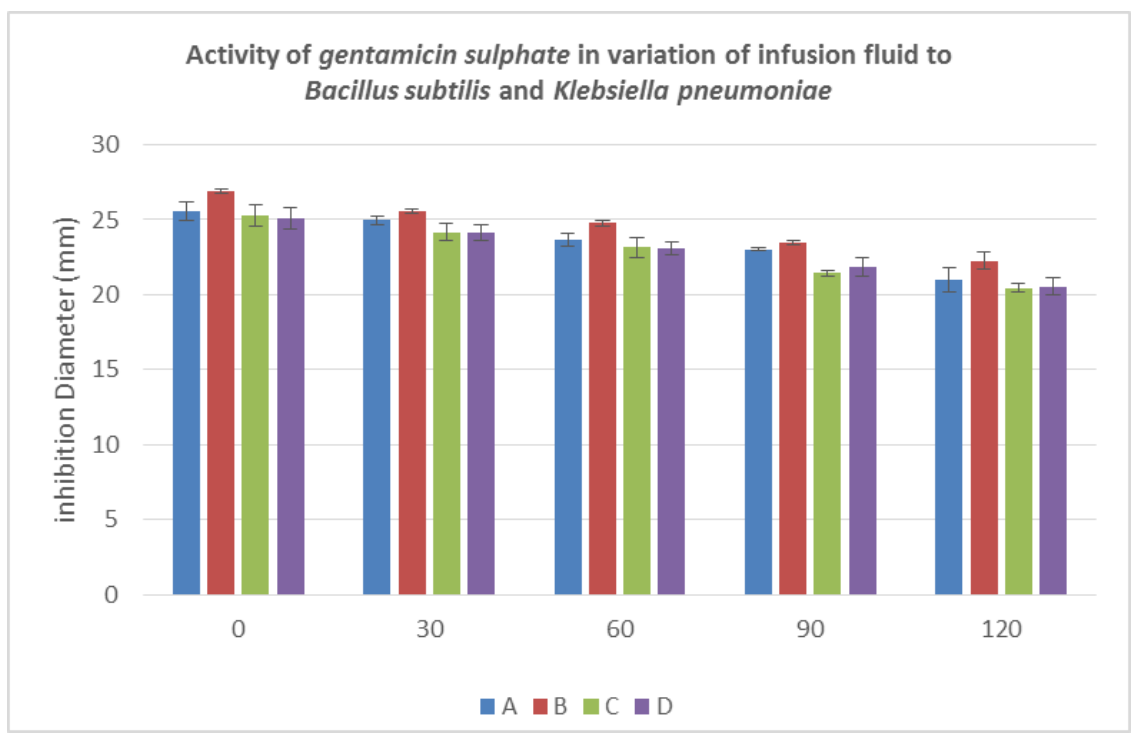

Fig. 1: Activity of gentamicin sulphate in variation of infusion fluid to Bacillus subtilis and Klebsiella pneumoniae

\section{Description:}

$\mathrm{A}=$ Inhibition zone diameter of Gentamicin Sulfate in $\mathrm{NaCl} 0.9 \%$ to Bacillus subtilis

B = Inhibition zone diameter of Gentamicin Sulfate in Dextrose 5\%$\mathrm{NaCl} 0.225 \%$ to Bacillus subtilis

$\mathrm{C}=$ Inhibition zone diameter of Gentamicin Sulfate in $\mathrm{NaCl} 0.9 \%$ to Klebsiella pneumoniae

$\mathrm{D}=$ Inhibition zone diameter of Gentamicin Sulfate in Dextrose 5\%$\mathrm{NaCl}$ 0.225\% to Klebsiella pneumoniae

From fig. 1, it could be seen that gentamicin sulfate has decreased activity when mixed with intravenous fluids, both $\mathrm{NaCl} 0.9 \%$ and Dextrose $5 \%-\mathrm{NaCl} 0.225 \%$. In both samples, there were a decrease in the inhibitory zone diameter of each mixing time increase. This could occur due to the instability of gentamicin sulfate in the intravenous fluids. Results from a study by Saptarini showed that the longer gentamicin sulfate stays in the infusion, the lesser the fluid levels will be. This decrease in gentamicin sulfate levels causes a decrease in antibiotic's sensitivity in killing bacteria, as indicated by the reduced inhibitory zone diameter. Since this is the case, the mixing should be done right after. If gentamicin stays too long in intravenous fluids, it will give the result to a very weak antibacterial activity. Weak antibacterial activity causes in effectiveness to the therapy, if it persists continuously and massively, it can be one of the triggers of bacterial resistance to antibiotics [8].

\section{Data analysis}

Although there were differences in inhibitory zones on the variation of infusion and time variation, data analysis was needed to see if the infusion variation and time variation have a significant effect on gentamicin sulfate activity in killing Bacillus subtilis and Klebsiella pneumoniae bacteria. This data analysis was done by ANOVA method using $\alpha$ equal to $5 \%(0.05)$. The results suggested variations in intravenous fluids, variations in time of use, and interactions between variations in intravenous fluids with the time of use having a significant effect on gentamicin sulfate activity when the significance value was less than $\alpha$ value (reject $\mathrm{H} 0$, receive $\mathrm{H} 1$ ).
Based on the results of ANOVA in Bacillus subtilis bacteria, significance value of time variation was 0.000 ; significance of infusion variation was 0.000 , and significance interaction of both was 0.253. Based on the results of ANOVA on Klebsiella pneumoniae bacteria, significance value of time variation was 0.000 ; significance of infusion variation was 0.768 , and the significance of their interaction was 0.923 .

Based on these results, it can be seen that the variation of infusion and variation of time of use significantly affect the activity of gentamicin sulfate to Bacillus subtilis bacteria, while the interaction between the variation of infusion fluid with the time of its use did not give a significant effect. In addition, the variation of time of use had a significant effect on gentamicin sulfate activity against the bacteria Klebsiella pneumoniae, whereas the variation of the infusion and the interaction between variations of intravenous fluids with a time of use did not give a significant effect.

The test may be continued by the Tukey method if the ANOVA result referred to H0. The test was performed to determine the best effect on gentamicin sulphate activity.

The most significant effect on gentamicin sulfate activity can be seen from the magnitude of the average difference. If the average difference was of positive value, it means that it gave a good effect, if the average difference was of negative value, it means that it gave a bad influence. The main differences in the time variation in bacteria Bacillus subtilis were as follows: minute to $0(+0.467)$; 30 th min of $(+0.366)$; minute to $60(+0.260)$; 90 th $\min$ of $(0.302)$; 120 th min $(-$ $0.467)$, while the average differences in time variation in Bacillus subtilis bacteria were as follows: minutes to $0(+0.467)$; 30 th $\mathrm{min}$ of $(+0.368)$; minutes to $60(+0.262)$; 90 th $\min$ of $(-0.354)$; 120 th $\min (-$ 0.467).

Based on the Tukey test results, the largest difference can be seen in minutes 0 and 120 compared to other mixing time variations. From the value of this average difference, it can also be determined which time variation that gives the best effect by looking at the largest average difference with a positive value [17]. The results showed that mixing time at minute 0 gave the best effect on gentamicin sulfate activity. In addition, it can also be seen that in the length of time mixing gentamicin sulfate with intravenous fluids it still gave a good influence, which was up to $60 \mathrm{~min}$. Mixing time at minute 90 , 
on the other hand, gave the worst effect. Thus, mixing should only be used either when it will be used on the spot or be used for $60 \mathrm{~min}$.

The following picture showed which variation of infusion fluid gave better influence to gentamicin sulfate activity:

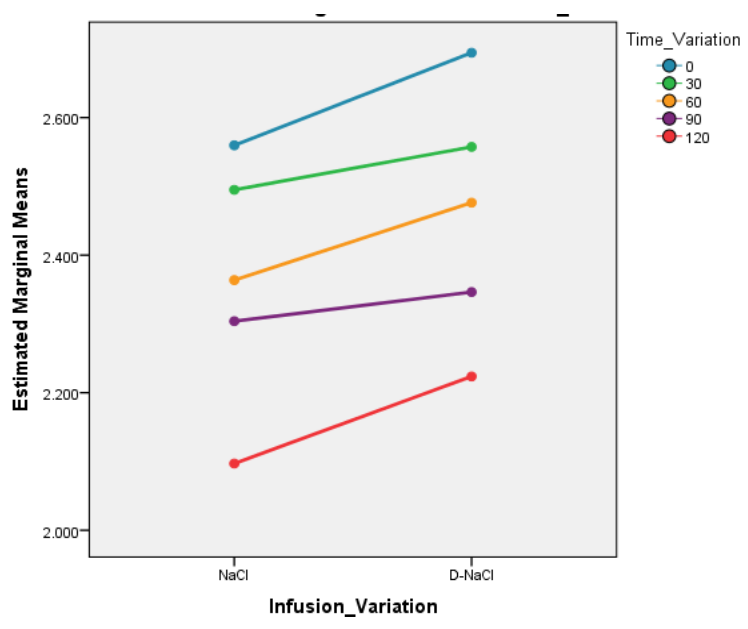

Fig. 2: Profile of sample activity against Bacillus subtilis

From fig. 2, it can be seen that at any time variation of use, gentamicin sulfate in the infusion of Dextrose $5 \%-\mathrm{NaCl} 0.225 \%$ always gave greater activity than gentamicin sulfate in a $0.9 \% \mathrm{NaCl}$ infusion. Thus, it can be concluded that the infusion of Dextrose 5\%$\mathrm{NaCl} 0.225 \%$ gave a better effect on gentamicin sulfate activity against Bacillus subtilis bacteria than $0.9 \% \mathrm{NaCl}$ infusion.

\section{CONCLUSION}

$\mathrm{NaCl}$ Infuson and Dextrose- $\mathrm{NaCl}$ had no effect on the activity of injection preparation of gentamicin sulfate against Klebsiella pneumoniae bacteria, but had an effect on Bacillus subtilis. The time of mixed use of gentamicin sulfate injection with $\mathrm{NaCl}$ and Dextrose$\mathrm{NaCl}$ infusion fluid gave effect to its activity on Bacillus subtilis and Klebsiella pneumoniae bacterias, where the longer mixing time gentamicin sulphate activity decreased. The interaction between the two intravenous fluids with the time of their use had no effect on the activity of injection of gentamicin sulfate against bacteria Bacillus subtilis and Klebsiella pneumoniae.

\section{ACKNOWLEDGEMENT}

The authors would like to thank the Directorate of Higher Education who had provided support in the form of funding for this research.

\section{AUTHORS CONTRIBUTIONS}

All the authors have contributed equally.

\section{CONFLICTS OF INTERESTS}

\section{Declare none}

\section{REFERENCES}

1. Brisse S, Fevre C, Passer V, Jeanjeanz SI. Virulent clones of Klebsiella pneumoniae: identification and evolutionary scenario based on the genomic and phenotypic characterization. Plos One 2009;4:1-13.

2. Ministry of Health RI. Guidelines for Pharmaceutical Services for Antibiotic Therapy. Jakarta; 2011.

3. Manggopa ON, Soeliongan S, Homenta H. Aerobic bacteria pattern on sputum patients with acute respiratory infection in lung polyclinic RSUP Prof. Dr. R. D. kandou manado. J E-Biomed 2016;4:1-5.

4. Rolanda E, Iskandarsyah, Soemiati A. Effect of liposomes encapsulation on antibacterial activity of Gentamicin Sulfate. [Thesis]. Jakarta: FMIPA, Indonesian University; 2012.

5. Divyashanthi CM, Adithiyakumar S, Bharathi N. Study of prevalence and antimicrobial susceptibility pattern of bacterial isolates in a tertiary care hospital. Int J Pharm Pharm Sci 2015; 7:185-90.

6. Taha NA, Yin TS, Said MM, Rahman RA. An investigation of errors: the preparation and administration of parenteral medications in an intensive care unit of a tertiary teaching hospital in Malaysia. Int J Pharm Pharm Sci 2016;8:325-9.

7. Ministry of Health RI. Guidelines for Injecting Injectable Drugs and Handling of Cytostatic Dosage. Jakarta; 2009.

8. Saptarini NM. Stability studies of Amoxicillin and Gentamicin injection in intravenous infusions. J Young Pharm 2015; 7:250-6.

9. Kang M, Ju-Seop K. Stability test of Ampicillin Sodium solutions in the accufuser ${ }^{\circledR}$ elastomeric infusion device using HPLC-UV method. Pharmacol Pharm 2012;3:462-7.

10. Santos CA, Laura ON, Marcos CK. Biological and physicochemical stability of ceftazidime and aminophylline on glucose parenteral solution. Braz J Pharm Sci 2012;48:691-8.

11. Pambudi AI, Sulistiyaningsih, Kurniawansyah IS. Injection activity of Gentamicin Sulfate in Ringer's lactate and ringer dextrose fluids on Klebsiella pneumoniae and Bacillus subtilis bacteria. [Thesis]. Jatinangor: Pharmacy Faculty, Padjadjaran University; 2015.

12. Kurniawansyah IS, Abdassah M, Selvamani S. Effectiveness of the class VI internal chemical indicator strip on steam sterilization of sodium chloride infusion. Int J Curr Pharm Rev Res 2016;7:237-42.

13. Sardian N, Litaay M, Budji RG. Potential of Rhopalaea sp as a source of inoculum bacteria endosymion antibacterial producer. J Nat Environ 2015;6:63-73.

14. Anggraini R, Aliza D, Melisa S. Identification of Aeromonas hydrophila bacteria with a microbial test on dumbo catfish (Clarias gariepinus) cultivated in district baitussalam regency of aceh besar. Sci J Marine Fisheries 2016;1:270-86.

15. Pratita MYE, Putra SR. Isolation and identification of thermophilic bacteria from hot springs source in songgoriti after two days of incubation. Pomits Technical J 2012;1:1-5.

16. Dima L, Fatimawali L, Lolo WA. Antibacterial activity test of kelor leaf extract (Moringa oleifera L.) against Escherichia coli and Staphylococcus aureus bacterias. Pharmacon 2016;5:282-9.

17. Irianto A. Basic concept statistics and their applications. Jakarta: Kencana; 2007.

18. Aryal S. Biochemical test and identification of Bacillus subtilis; 2016. Available from: http://www.microbiologyinfo.com/ biochemicaltest-and-identification-of-bacillus-subtilis/ [Last accessed on 10 Jun 2017].

19. Aryal S. Biochemical Test and Identification of Klebsiella pneumoniae; 2016. Available from: http://www.Microbiologyinfo.com/biochemical-test-and-identification-of-klebsiellapneumoniae/ [Last accessed on 10 Jun 2017]. 